\title{
Importance of domain-specific metacognition for explaining beliefs about politicized science: The case of climate change
}

\author{
Helen Fischer ${ }^{1 *}$ \& Nadia Said ${ }^{2,3}$ \\ ${ }^{1}$ Stockholm Resilience Centre, Complex Adaptive Systems and Resilience Thinking Stream, Kräftriket \\ 2B, 10691 Stockholm, Sweden \\ ${ }^{2}$ Interdisciplinary Center for Scientific Computing (IWR), Heidelberg University. Im Neuenheimer \\ Feld 205, 69120 Heidelberg, Germany \\ ${ }^{3}$ Department of Psychology, Heidelberg University. Hauptstrasse 47-51, 69117 Heidelberg, Germany
}

*Corresponding author. Helen Fischer. Stockholm Resilience Centre, Complex Adaptive Systems and Resilience Thinking Stream, Kräftriket 2B, 10691 Stockholm, Sweden. Permanent e-mail: helen.fischer@posteo.de.

Declarations of interest: none. 


\section{Highlights}

- Meta-knowledge, or confidence in knowledge, explains beliefs about politicized science

- Holds above and beyond object-level knowledge of the science, and political attitude

- Results are domain-specific: Only meta-knowledge that is relevant for the domain explains scientific beliefs

One of the oldest debates in psychological research into politicized science such as nanotechnology, vaccination, or climate change centers around the role of knowledge: Does increased knowledge of the science affect beliefs about it? While research has traditionally focused on the role of object-level knowledge, here we highlight the importance of meta-knowledge, or confidence in knowledge. Specifically, we demonstrate the importance of meta-knowledge for explaining beliefs about science with one of the most contested examples: climate change. Across two national samples from Germany (total $\mathrm{N}=1,097$ ), frequentist and Bayesian analyses demonstrated that climate change meta-knowledge was predictive of climate change beliefs, above and beyond object-level climate change knowledge. These results held for both the belief that climate change is risky, and the belief that climate change is anthropogenic, and when controlling for political attitude, and demographic variables. Furthermore, confidence in other-domain (biological and physical) science knowledge explained climate change beliefs considerably less compared to domain-specific knowledge, suggesting that outside the domain for which it was relevant, confidence in science knowledge was largely irrelevant for shaping beliefs. These results highlight the relevance of domain-specific metacognition for explaining beliefs about the contested science of climate change. By demonstrating the relevance of metacognitive, rather than solely object-level thought, these results add to our understanding of the cognitive mechanisms involved in the formation of beliefs about politicized science.

Keywords: Politicized science, climate change, metacognition. 
One of the oldest and most fundamental questions on the determinants of beliefs about politicized science such as nanotechnology, vaccination, or climate change, centers around the role of knowledge: Does increased knowledge of the science affect beliefs about it? While considerable research exists on the explanatory role of object-level cognition (Hornsey et al., 2016; Shi et al., 2016), here we highlight the importance of metacognition. Specifically, we demonstrate the role of metaknowledge (or confidence in knowledge; Fleming \& Lau, 2014) for explaining beliefs about science with one of the most contested examples: climate change (Drummond \& Fischhoff, 2017). In the area of climate change, citizens are confronted with a mix of accurate information, and misinformation (Del Vicario et al., 2016; Jasny et al., 2015; Vosoughi et al., 2018) that constantly challenges the credibility of citizens’ existing knowledge. In such a potentially confusing information environment, metaknowledge could serve as a critical guide when forming beliefs supported by knowledge, particularly when unequivocal external feedback about the accuracy of knowledge is absent.

It is virtually unknown, however, whether meta-knowledge and metacognitive sensitivity (knowing what you know, and what you don't) relate to climate change beliefs. This is highly surprising given strong theoretical reasons to suspect such a relationship. First, with respect to confidence in knowledge, it was found that knowledge is translated into congruent judgment only when it is held with sufficiently high confidence, even when controlling for the accuracy of knowledge (Allgood \& Walstad, 2016; Hadar et al., 2013). Hence, higher confidence in climate change knowledge may increase the likelihood of this knowledge being translated into congruent belief. And second, with respect to sensitivity, (i) to form beliefs supported by knowledge, as well as to (ii) to update knowledge in light of novel information (Kube et al., 2020), citizens need insight into which pieces of their currently held knowledge are incorrect and should be trusted, and which ones are correct and should not be trusted. Hence, domain-specific metacognitive sensitivity may explain climate change beliefs, above and beyond the accuracy of object-level climate change knowledge.

Here we investigate whether, and in how far domain-specific metacognition explains climate change beliefs, above and beyond object-level knowledge in a nationally balanced quota sample of German citizens. For clarity, we use the term subjective knowledge to refer to previously used one-item measurement of participants' subjective assessment of their knowledge (e.g., "How informed do you consider yourself to be about global warming?”; Kellstedt et al., 2008), which precludes estimating different facets of metacognition; we use the term domain-specific metacognition, when participants 
indicate after each objective knowledge item how confident they are that they answered correctly, which allows estimating different facets of metacognition.

\section{Objective and subjective climate change knowledge and beliefs}

In line with previous research, we define beliefs as statements about the truth value of a given proposition (Wolfe \& Williams, 2018). Beliefs are distinct from knowledge in that people can have knowledge of claims (such as that climate change is mainly caused by fossil fuel emissions) without believing them to be true. We define knowledge operationally as accurate answers to declarative statements, with accuracy--in the present case of climate change--, defined in terms of correspondence to scientific consensus as described in the IPCC reports.

To test the relationship between climate change knowledge and beliefs, studies using subjective knowledge as a measure of objective knowledge yielded results that vay in accordance to political attitude. The feeling to know more about global warming was positively associated with concern for Democrats, but unrelated for Republicans, and greater self-reported understanding of climate change was positively associated with concern for liberals and Democrats, but negatively so for Republicans (Malka et al., 2009). Furthermore, within 10 nationally representative US polls between 2001 and 2010, self-reported understanding was positively associated with concern over climate change for liberals and Democrats, and more weakly so or even negatively so for conservatives and Republicans (McCright \& Dunlap, 2011b). Drawing on the same data, denial of climate change was highest among white male conservatives who claim to understand climate change very well (McCright \& Dunlap, 2011a).

As opposed to subjective measures, objective measures of climate change knowledge tend to show a consistently positive (albeit small) predictive value of climate change knowledge for climate change beliefs. A large study among citizens from Switzerland found that those who know more about climate change tended to be more concerned (Tobler et al., 2012), understanding of the causes of global warming was the single best predictor of behavioral intentions to act on global warming among 1218 Americans (Bord et al., 2000), knowledge about the causes of climate change predicted concern about climate change in six politically and culturally diverse countries (Shi et al., 2016), and in 119 countries, understanding the anthropogenicity of climate change even proved the strongest predictor of climate change risk perceptions (Lee, Markowitz, Howe, Ko \& Leiserowitz, 2015). 
In terms of the size of the variance explained by knowledge, estimates range between $2 \%$ to 18\% for different countries (Shi et al., 2016), and an average estimate of 6.3\% was revealed by a metaanalysis (Hornsey et al., 2016).

\section{Metacognition and beliefs about politicized issues}

There is emerging evidence that domain-general metacognitive ability such as cognitive flexibility can shape beliefs about politicized issues. Specifically, it was found that lower metacognitive sensitivity measured in a perceptual task predicted extremeness of political beliefs (Rollwage et al., 2018), and that cognitive flexibility measured with the Wisonsin Task and the Remote Associates Test predicted beliefs about Brexit (Zmigrod et al., 2018), as well as violence to protect the national ingroup (Zmigrod et al., 2019). Furthermore, differences in the degree of belief updating after feedback were found to be predictive of right-wing authoritarianism (Sinclair et al., 2019). While these results underscore the relevance of domain-general metacognitive ability for explaining citizens’ political beliefs and attitudes, considerably less is known about whether and how domain-specific metaknowledge is related to beliefs about politicized science.

\section{The present study}

The current research extends existing research in three important aspects. First, it was found that subjective measures of climate change knowledge tend to explain less variance in climate change beliefs compared to objective measures (for a meta-analysis, see Hornsey et al., 2016). Here we argue, however, that when understood as a measure of objective knowledge, subjective measures of knowledge do represent an unreliable proxy. But subjective beliefs about the degree of one’s

knowledge capture additional, and different information that is not represented in measures of objective knowledge, namely domain-specific metacognition. Moreover, the typical result of lower predicitivity subjective compared to objective knowledge may be a methodological artifact since subjective knowledge was typically assessed using one-item measures, whereas objective knowledge was measured using whole scales. Using single-item measures, the reliability of the confidence scale is unknown (and unknowable). The lower predicitvity could hence be the result of subjective knowledge not only being a less reliable measure of objective knowledge, but also an un-reliable measure of subjective knowledge itself. Here we use a repeated assessment of confidence in knowledge that allows estimating the reliability of the confidence scale. 
Second, as subjective knowledge was typically understood as a proxy of objective knowledge, previous studies did not investigate the predictive value of subjective knowledge, controlling for objective knowledge. One notable exception is a study that found that subjective knowledge was a negative, and objective knowledge a positive predictor of climate change concern (Stoutenborough \& Vedlitz, 2014). However, this study also used a global assessment of subjective knowledge ("How informed do you consider yourself to be?”) that cannot be directly mapped on the objective knowledge scale, and hence does not allow for estimating sensitivity. Here we use a repeated measurement of confidence that allows determining how different facets of metacogntion relate to beliefs, above and beyond knowledge.

And third, climate change knowledge items typically have the form of true/false statements such as "Burning oil produces $\mathrm{CO}_{2}$ " (Shi et al., 2016), and accuracy is determined with reference to scientific consensus, that is, relative to external reality. However, citizens might answer knowledge questions not in accordance to what science beliefs, but what they personally believe, that is, relative to internal reality. For example, citizens might well know that science says that burning oil produces $\mathrm{CO}_{2}$, but still answer FALSE, simply because they themselves do not hold the statement to be true. Such response patterns can (i) bias the relationship between knowledge and beliefs; and (ii) confound assessment of knowledge with assessment of beliefs. Here we introduce each climate change knowledge statement with: "Science says that...”, thereby explicitly specifying that participants should answer in accordance to science's belief about climate change.

The goal of the study is to investigate whether domain-specific metacognition predicts climate change beliefs (a) not at all, (b) in addition to knowledge, (c) in interaction with knowledge, or (c) at the expense of knowledge.

\section{Study 1}

\section{Methods}

All data for study 1 and study 2 are freely accessible under https://osf.io/dwbt2/. The code (in R) to reproduce all results and figures will be made freely accessible prior to publication. For both study 1 and study 2, we analyzed data that have been collected as part of a different project (Fischer et al., 2019).

Participants. A total of N=509 German citizens were recruited over the polling company YouGov. The sample constitutes a nationally balanced quota sample with respect to gender (female: $\mathrm{n}=$ 
267, 53\%), age (mean=48.5, range $=18-88$ ), and geographical distribution. Participants had a range of educational backgrounds (lowest school leaving certificate: 14\%; middle school leaving certificate: 39\%; highest school leaving certificate: 20\%; Bachelor: 7\%; Master: 13\%, PhD: 1\%; other: 4\%; nine participants did not indicate their education), and a wide range of professions.

Procedure. The survey was conducted in the following order: Political view, climate change beliefs, knowledge and meta-knowledge, demographics.

\section{Measures}

Climate change knowledge. Participants judged a total of eight statements about climate change (four TRUE, four FALSE) taken from previous research (Sundblad et al., 2009). Each statement started with "Science says that...”. Participants answered “yes, science says that”, or "no, science does not say that”. In contrast to previous research (Tobler et al., 2012), an “I don't-know”-option was not given. This was done (i) to assess meta-knowledge using a full-range scale as opposed to a binary statement, (ii) to assess any partial knowledge participants may have, and (iii) because people are deferentially adverse to guessing an answer, leading to biased knowledge scores due to skipped items (Baldiga, 2013).

The knowledge statements covered the areas of causes, state, and consequences of climate change, and were: The global average temperature in the air has increased approx. $3.1{ }^{\circ} \mathrm{C}$ in the past 100 years. (False); The 1990s was the warmest decade during the past 100 years. (False); The global change in temperature in the past 100 years is the largest during the past 1,000 years. (True); Climate change is mainly caused by a natural variation in sunbeam and volcanic eruption. (False); Carbon dioxide concentration in the atmosphere has increased more than 30\% during the past 250 years. (True); The increase of greenhouse gases is mainly caused by human activities. (True); The blanket of snow in the Northern Hemisphere has decreased approximately 10\% since the 1960s. (True); An increasing amount of greenhouse gases increases the risk of more UV-radiation and therefore a larger risk of skin cancer. (False).

Meta-knowledge. Participants indicated, after each knowledge item: "How certain are you that your answer is correct?” on a 6-point scale ranging from 50\% to $100 \%$, where all ticks were labeled with \%-values, and the scale end point additionally had verbal descriptions (“50\%: not at all certain, I was guessing”; “100\%: certain, I know the answer”). Reliability of the confidence scale was high, alpha $_{\text {study1 }}=0.86[0.84,0.88] ;$ alpha $_{\text {study2 }}=0.87[0.85,0.89]$. 
Political orientation. Participants indicated "When talking about politics, one often hears the concepts "left” and "right”. We would like to know from you where you would place yourself” on a 9point scale (1: left; 9: right).

Climate change beliefs. Participants indicated: "How much do you agree with the following statements: 1. "Climate change is mostly caused by humans” and. 2. "Climate change is risky”, each on a 5-point scale (“1: I don’t agree at all”; 5: “I totally agree”). Correlation between belief items was high, $\mathrm{r}_{\text {study1 }}(507)=.64,95 \% \mathrm{CI}=[.59, .69] ; \mathrm{r}_{\text {study2 }}(586)=.61,95 \% \mathrm{CI}=[.56, .67]$.

\section{Analysis}

Knowledge. To measure the accuracy of knowledge, we used $d$ ' as specified in a Signal Detection Theory (SDT) framework, by quantifying the difference between the z-transformed True Positive, and the z-transformed False Positive rate in the knowledge test.

Meta-knowledge. To measure meta-knowledge, we use participants' mean confidence in their knowledge (Fleming \& Lau, 2014). Since confidence also reflects participants’ general tendency to report high or low confidence judgments, mean confidence is indicative of metacognitive bias.

Metacognitive sensitivity. As a bias-free measure of metacognitive accuracy, sensitivity, we use meta_d' (Maniscalco \& Lau, 2014). Meta_d expresses metacognitive sensitivity in an SDT framework, and assesses the degree to which participants’ confidence judgments reflect accurate versus inaccurate responses to the knowledge items, controlling for their response bias. To compute meta_d, we used a hierarchical Bayes procedure (Fleming, 2017), and code provided at https://github.com/smfleming/HMeta-d.

\section{Results and Discussion}

Descriptive results on the distribution of political attitude and climate change beliefs is given in Figure 1. Means, standard deviations and correlations of all measures used in this study are given in Table 1. 

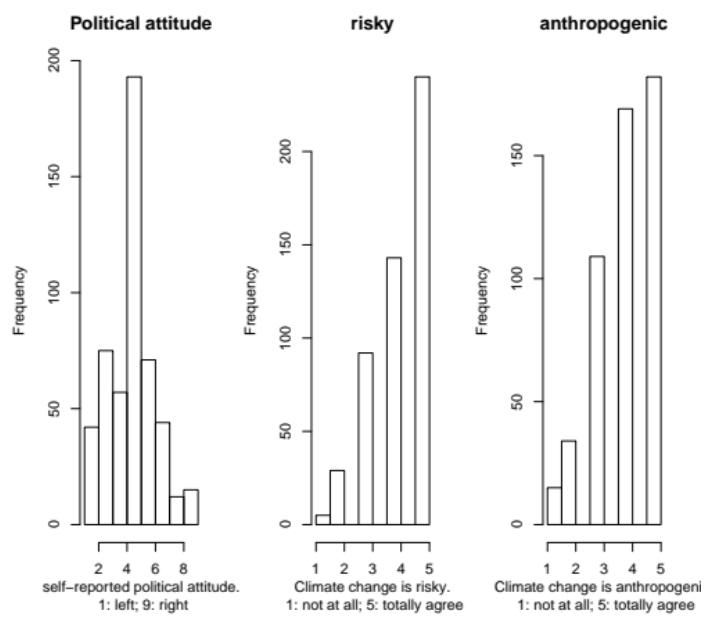

Fig. 1. Distributions of self-reported political attitude, beliefs that climate change is risky, and beliefs that climate change is anthropogenic.

Table 1. Means, standard deviations, and correlations of measures used in study 1.

\begin{tabular}{|c|c|c|c|c|c|c|}
\hline Variable & $M$ & $S D$ & 1 & 2 & 3 & 4 \\
\hline 1. anthropogenic & 3.92 & 1.05 & & & & \\
\hline 2. risky & 4.15 & 0.97 & $\begin{array}{c}.64 * * \\
{[.59, .69]}\end{array}$ & & & \\
\hline 3. knowledge (d') & 0.61 & 0.15 & $\begin{array}{l}.20 * * \\
{[.11, .28]}\end{array}$ & $\begin{array}{l}.18 * * \\
{[.09, .26]}\end{array}$ & & \\
\hline $\begin{array}{l}\text { 4. meta-knowledge } \\
\text { (confidence) }\end{array}$ & 0.72 & 0.12 & $\begin{array}{l}.16^{* *} \\
{[.08, .25]}\end{array}$ & $\begin{array}{c}.24^{* *} \\
{[.16, .32]}\end{array}$ & $\begin{array}{l}.19^{* *} \\
{[.10, .27]}\end{array}$ & \\
\hline $\begin{array}{l}\text { 5. metacognitive } \\
\text { sensitivity (meta_d) }\end{array}$ & 0.21 & 0.57 & $\begin{array}{c}.14^{* *} \\
{[.05, .22]}\end{array}$ & $\begin{array}{l}.14^{* *} \\
{[.06, .23]}\end{array}$ & $\begin{array}{l}.24^{* *} \\
{[.15, .32]}\end{array}$ & $\begin{array}{c}.39 * * \\
{[.32, .46]}\end{array}$ \\
\hline
\end{tabular}

Note. $M$ and $S D$ are used to represent mean and standard deviation, respectively. Values in square brackets indicate the $95 \%$ confidence interval for each correlation. * indicates $p<.05$. ** indicates $p$ $<.01$. 
Table 2. Multiple regression analyses predicting belief that climate change is anthropogenic from climate change knowledge, meta-knowledge (confidence), and metacognitive sensitivity (meta_d), controlling for political attitude (1: left; 9: right), gender (1= male; 2 = female), age, and education (dummy-coded).

\begin{tabular}{|c|c|c|c|c|c|c|}
\hline Predictor & $\boldsymbol{b}$ & $\begin{array}{c}b \\
95 \% \text { CI } \\
\end{array}$ & beta & $\begin{array}{c}\text { beta } \\
95 \% \text { CI } \\
\end{array}$ & Fit & Difference \\
\hline (Intercept) & $4.43^{* *}$ & {$[3.83,5.02]$} & & & & \\
\hline $\mathrm{d}$ & $0.25^{* *}$ & {$[0.12,0.38]$} & 0.17 & {$[0.08,0.26]$} & & \\
\hline Political & - & & & & & \\
\hline Attitude & $0.09 * *$ & {$[-0.14,-0.03]$} & -0.14 & {$[-0.23,-0.05]$} & & \\
\hline sex & -0.07 & {$[-0.26,0.12]$} & -0.03 & {$[-0.12,0.06]$} & & \\
\hline age & -0.00 & {$[-0.01,0.00]$} & -0.04 & {$[-0.13,0.05]$} & & \\
\hline \multirow[t]{5}{*}{ education } & 0.01 & {$[-0.06,0.08]$} & 0.01 & {$[-0.08,0.10]$} & & \\
\hline & & & & & $R^{2}$ & \\
\hline & & & & & $=.063 * *$ & \\
\hline & & & & & $95 \%$ & \\
\hline & & & & & CI[.02,.10] & \\
\hline (Intercept) & $3.69 * *$ & {$[2.86,4.52]$} & & & & \\
\hline d' & $0.23 * *$ & {$[0.09,0.36]$} & 0.15 & {$[0.06,0.24]$} & & \\
\hline Political & - & & & & & \\
\hline Attitude & $0.08 * *$ & {$[-0.14,-0.02]$} & -0.13 & {$[-0.22,-0.04]$} & & \\
\hline sex & -0.02 & {$[-0.21,0.17]$} & -0.01 & {$[-0.10,0.08]$} & & \\
\hline age & -0.00 & {$[-0.01,0.00]$} & -0.06 & {$[-0.15,0.03]$} & & \\
\hline education & -0.01 & {$[-0.08,0.07]$} & -0.01 & {$[-0.10,0.08]$} & & \\
\hline \multirow[t]{4}{*}{ confidence } & $1.05^{*}$ & {$[0.23,1.88]$} & 0.12 & {$[0.03,0.21]$} & & \\
\hline & & & & & $\begin{array}{l}R^{2} \\
=.076 * *\end{array}$ & $\Delta R^{2}=.012^{*}$ \\
\hline & & & & & $95 \%$ & $95 \%$ \\
\hline & & & & & CI[.03,.11] & CI[-.01, .03] \\
\hline (Intercept) & $3.75^{* *}$ & {$[2.91,4.59]$} & & & & \\
\hline d' & $0.22 * *$ & {$[0.08,0.35]$} & 0.15 & {$[0.05,0.24]$} & & \\
\hline polAttitude & $\overline{-}-08 * *$ & {$[-0.14,-0.02]$} & -0.13 & {$[-0.22,-0.04]$} & & \\
\hline sex & -0.01 & {$[-0.20,0.18]$} & -0.01 & {$[-0.10,0.08]$} & & \\
\hline age & -0.00 & {$[-0.01,0.00]$} & -0.06 & {$[-0.15,0.03]$} & & \\
\hline education & -0.01 & {$[-0.08,0.07]$} & -0.01 & {$[-0.10,0.08]$} & & \\
\hline confidence & $0.92 *$ & {$[0.04,1.79]$} & 0.10 & {$[0.01,0.20]$} & & \\
\hline \multirow[t]{4}{*}{ meta_d } & 0.08 & {$[-0.09,0.26]$} & 0.05 & {$[-0.05,0.14]$} & & \\
\hline & & & & & $\begin{array}{l}R^{2} \\
=.077 * *\end{array}$ & $\Delta R^{2}=.002$ \\
\hline & & & & & $95 \%$ & $95 \%$ \\
\hline & & & & & CI[.03,.11] & CI[-.01, .01] \\
\hline
\end{tabular}

Note. $b$ represents unstandardized regression weights. beta indicates the standardized regression weights. * indicates $p<.05$. ** indicates $p<.01$. 
Table 3. Multiple regression analyses predicting belief that climate change is risky, using climate change knowledge, meta-knowledge (confidence), and metacognitive sensitivity (meta_d), controlling for political attitude (1: left; 9: right); gender ( $1=$ male; 2 = female), age, and education (dummy-coded).

\begin{tabular}{|c|c|c|c|c|c|c|}
\hline Predictor & $\boldsymbol{b}$ & $\begin{array}{c}b \\
95 \% \mathrm{CI} \\
\end{array}$ & beta & $\begin{array}{c}\text { beta } \\
95 \% \text { CI }\end{array}$ & Fit & Difference \\
\hline (Intercept) & $4.23 * *$ & {$[3.69,4.77]$} & & & & \\
\hline d' & $0.19 * *$ & {$[0.07,0.31]$} & 0.14 & {$[0.05,0.23]$} & & \\
\hline $\begin{array}{l}\text { Political } \\
\text { Attitude }\end{array}$ & $-0.11^{* *}$ & {$[-0.16,-0.05]$} & -0.19 & {$[-0.28,-0.10]$} & & \\
\hline sex & -0.03 & {$[-0.20,0.14]$} & -0.02 & {$[-0.10,0.07]$} & & \\
\hline age & $0.01^{*}$ & {$[0.00,0.01]$} & 0.10 & {$[0.02,0.19]$} & & \\
\hline \multirow[t]{2}{*}{ education } & 0.02 & {$[-0.04,0.09]$} & 0.03 & {$[-0.06,0.12]$} & & \\
\hline & & & & & $\begin{array}{l}R^{2}=.080 * * \\
95 \% \\
\text { CI[.03,.12] }\end{array}$ & \\
\hline (Intercept) & $3.24 * *$ & {$[2.49,3.99]$} & & & & \\
\hline d' & $0.16^{*}$ & {$[0.04,0.28]$} & 0.12 & {$[0.03,0.21]$} & & \\
\hline $\begin{array}{l}\text { Political } \\
\text { Attitude }\end{array}$ & $-0.10^{* *}$ & {$[-0.15,-0.05]$} & -0.17 & {$[-0.26,-0.08]$} & & \\
\hline sex & 0.04 & {$[-0.13,0.21]$} & 0.02 & {$[-0.07,0.11]$} & & \\
\hline age & 0.00 & {$[-0.00,0.01]$} & 0.07 & {$[-0.02,0.16]$} & & \\
\hline education & 0.00 & {$[-0.07,0.07]$} & 0.00 & {$[-0.09,0.09]$} & & \\
\hline \multirow[t]{2}{*}{ confidence } & $1.41^{* *}$ & {$[0.67,2.15]$} & 0.18 & {$[0.08,0.27]$} & & \\
\hline & & & & & $\begin{array}{l}R^{2}=.106^{* *} \\
95 \% \\
\text { CI[.05,.15] }\end{array}$ & $\begin{array}{l}\Delta R^{2}=.026 * * \\
95 \% \\
\text { CI[-.00,.05] }\end{array}$ \\
\hline (Intercept) & $3.26 * *$ & {$[2.50,4.01]$} & & & & \\
\hline d' & $0.16^{*}$ & {$[0.03,0.28]$} & 0.12 & {$[0.02,0.21]$} & & \\
\hline $\begin{array}{l}\text { Political } \\
\text { Attitude }\end{array}$ & $-0.10 * *$ & {$[-0.15,-0.05]$} & -0.17 & {$[-0.26,-0.08]$} & & \\
\hline sex & 0.04 & {$[-0.13,0.21]$} & 0.02 & {$[-0.07,0.11]$} & & \\
\hline age & 0.00 & {$[-0.00,0.01]$} & 0.07 & {$[-0.02,0.16]$} & & \\
\hline education & 0.00 & {$[-0.07,0.07]$} & 0.00 & {$[-0.09,0.09]$} & & \\
\hline confidence & $1.38 * *$ & {$[0.59,2.16]$} & 0.17 & {$[0.07,0.27]$} & & \\
\hline \multirow[t]{2}{*}{ meta_d } & 0.02 & {$[-0.14,0.18]$} & 0.01 & {$[-0.08,0.11]$} & & \\
\hline & & & & & $\begin{array}{l}R^{2}=.106^{* *} \\
95 \% \\
\text { CI[.05,.15] }\end{array}$ & $\begin{array}{l}\Delta R^{2}=.000 \\
95 \% \\
\text { CI }[-.00, .00]\end{array}$ \\
\hline
\end{tabular}

Note. $b$ represents unstandardized regression weights. beta indicates the standardized regression weights. $*$ indicates $p<.05 .{ }^{* *}$ indicates $p<.01$. 


\section{Metacognition as a predictors of climate change beliefs: frequentist and Bayesian}

regression. We estimated in how far different aspects of climate change metacognition predict climate change beliefs above and beyond knowledge. We first ran four multiple ordinary least squares (OLS) regression models, separately for each climate change belief (risky, anthropogenic), with knowledge (d'), political attitude, and demographic variables (gender, age, education) as the baseline model, and subsequently entering meta-knowledge (confidence) and meta-cognitive sensitivity (meta_d) (Table 2, Table 3). Results showed that, for both climate change beliefs, meta-knowledge predicted climate change beliefs above and beyond the baseline model.

We additionally ran Bayesian regression analyses, again separately for both climate change beliefs. To calculate the Bayes factors, we used a default specification of priors (Wetzels et al., 2011), as implemented in the R package BayesFactor. Bayesian regression selects the best model from all possible combinations of predictors, where the best model is the one that balances parsimony and predictivity. The Bayesian analysis corroborated results from the frequentist analysis. Specifically, Bayesian regression revealed that, for both climate change beliefs, the best model was one that included knowledge (d') + political attitude + meta-knowledge (confidence). The Bayes Factors for this model were $\mathrm{BF}_{10 \_ \text {risky }}=112,639,478$ and $\mathrm{BF}_{10 \_ \text {anthropogenic }}=72,046$, respectively, indicating that the data were approx. 112 million, and 72.000 times more likely under this model compared to under the intercept-only model.

We tested whether the influence of meta-knowledge changes as a function of the level of objectlevel knowledge. Differential influence of meta-knowledge could emerge if, for example, participants with low levels of knowledge were particularly prone to relying on their subjective confidence. However, this largely appeared not to be the case in that the relationship between metacognitive confidence and climate change beliefs did not vary for different levels of climate change knowledge (Fig. 2). Rather, higher levels of confidence in knowledge related to increased climate change beliefs for all levels of knowledge. 

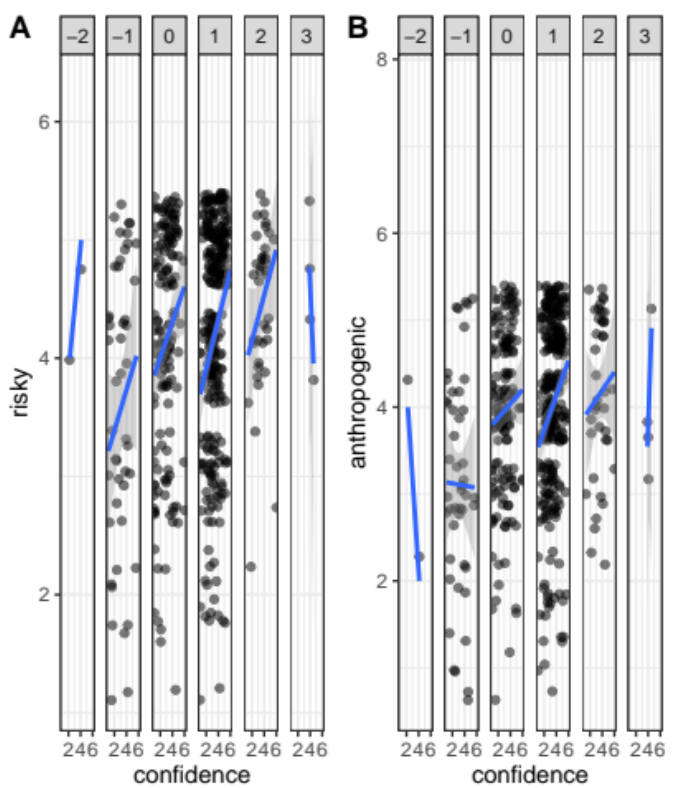

Figure 2. Relationship between meta-knowledge (confidence) and climate change beliefs (risky, Panel A; anthropogenic, Panel B), for different levels of climate change knowledge (d', rounded). Dots represent individual participants. Shaded grey area denotes 95\% CI.

Knowledge, meta-knowledge and political attitude. We first determined in how far climate change is a politicized subject among German citizens by correlating climate change beliefs with selfreported political attitude. As Figure 3 shows, a moderate negative relationship was revealed, r (484)= -.27, 95\% CI=[-.35, -.18], indicating that participants who self-identify as on the right of the political spectrum tended to indicate lower belief that climate change is risky, and that it is anthropogenic.
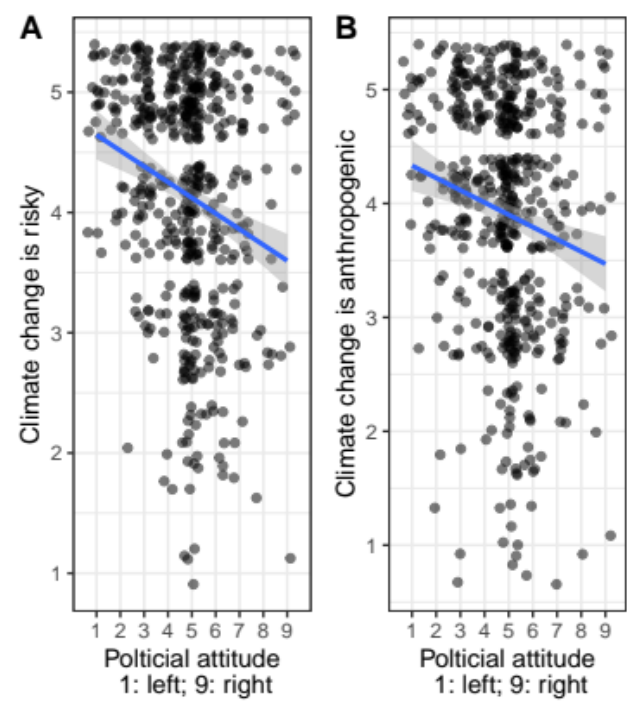
Figure 3. Self-reported political attitude (left:1, right: 9) and climate change beliefs (risky, Panel A and anthropogenic, Panel B). Dots represent individual participants. Shaded grey area represents $95 \%$ confidence band.

We investigated whether the predictive value of knowledge and different facets of metaknowledge change across the political spectrum as indicated by previous research using one-shot measures of subjective knowledge (Malka et al., 2009; McCright \& Dunlap, 2011a). As Figure 4 shows, this largely appeared not to be the case, in that the direction of the association was revealed to be broadly similar across the political spectrum. One potential exception are extreme values of political attitude that do, however, render low cell sizes and large estimation error.
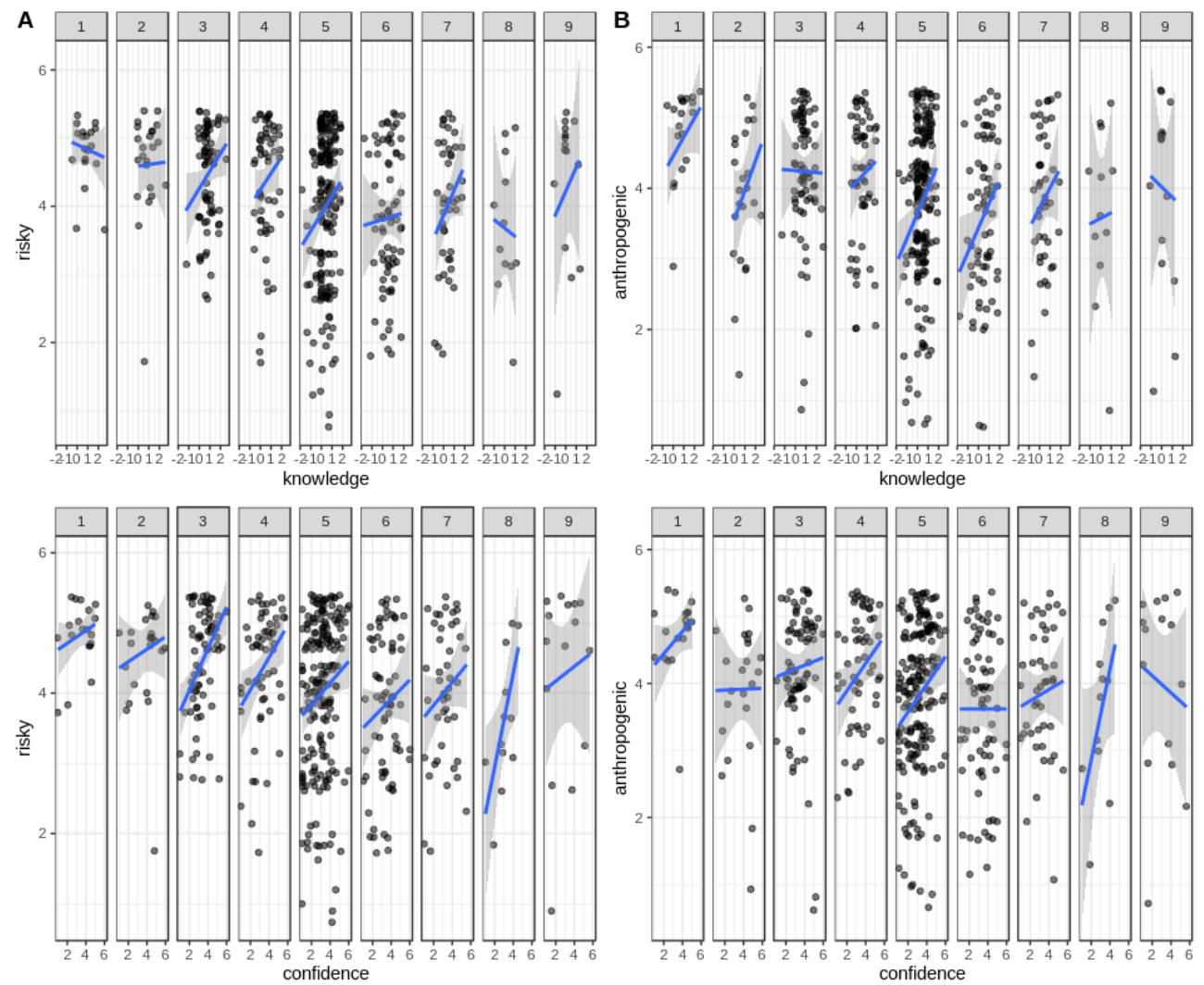

Figure 4. Relationship between knowledge (d') and meta-knowledge (confidence) and climate change beliefs (risky, Panel A; and anthropogenic, Panel B) across the spectrum of political attitude (selfreport; 1: left; 9: right). Dots represent individual participants. Shaded grey area denotes 95\% CI. 
Study 1 highlighted the importance of confidence in knowledge (but not sensitivity of confidence) for explaining beliefs about the politicized subject of climate change. Specifically, confidence in climate change knowledge predicted climate change beliefs above and beyond objectlevel knowledge. This held for both frequentist regression, and Bayesian regression, for both the belief that climate change is risky, and the belief that it is anthropogenic, and irrespective of political attitude, or level of climate change knowledge.

Although these results clearly show that confidence in knowledge predicted climate change beliefs, they do not conclusively demonstrate that it is domain-specific confidence that relates to beliefs. Rather, such a relationship could also be produced by more general causal mechanisms by which participants with higher confidence in scientific knowledge in general also tend to have higher climate change beliefs (confidence in science-knowledge explanation).

\section{Study 2}

Study 2 tested in how far study 1 results are domain-specific. Specifically, study 2 aimed at ruling out that confidence in science-knowledge could explain the relationship between confidence in climate change knowledge, and climate change beliefs. To do so, study 2 assessed knowledge and meta-knowledge in other-domain (biological and physical) science. If the degree of confidence in science knowledge explains climate change beliefs, we should find that other-science metacognitive confidence should predict higher climate change beliefs as well. To the extent that results of study 1 are domain-specific, however, metacognition of other-science knowledge should not explain climate change beliefs.

\section{Methods}

Participants. A total of N=588 German citizens were recruited over the polling company YouGov. The sample constitutes a nationally balanced quota sample with respect to gender (female: $\mathrm{n}=$ 303, 51\%), age (mean= 48.3, range $=18-88)$, and geographical distribution. Participants had a range of educational backgrounds, (lowest school leaving certificate: 15\%; middle school leaving certificate: 36\%; highest school leaving certificate: 23\%; Bachelor: 8\%; Master: 11\%, PhD: 1\%; other: 4\%; fourteen participants did not indicate their education), and a wide range of professions.

Procedure. The procedure was identical to study 1. 
Materials. To assess knowledge of biological and physical science, we used statements taken from statements about biological and physical sciences. Statements were taken from the National Science Board's Science and Engineering Indicators. Participants judged a total of nine statements about general scientific facts in biology and physics (five TRUE, four FALSE): The center of the Earth is very hot. (True); The continents on which we live have been moving their locations for millions of years and will continue to move in the future. (True); The Sun goes around the Earth. (False); All radioactivity is man-made. (False); Electrons are smaller than atoms. (True); Lasers work by focusing sound waves. (False); It is the father's gene that decides whether the baby is a boy or a girl. (True); Antibiotics kill viruses as well as bacteria. (False); The universe began with a huge explosion. (True).

The assessment of all other measures was identical to study 1.

Analysis. The computation of all indices was identical to study 1.

\section{Results and Discussion}

Descriptive results on the distribution of political attitude and climate change beliefs is given in Figure 5. Descriptive results for all measures used in study 2 are given in Table 4.
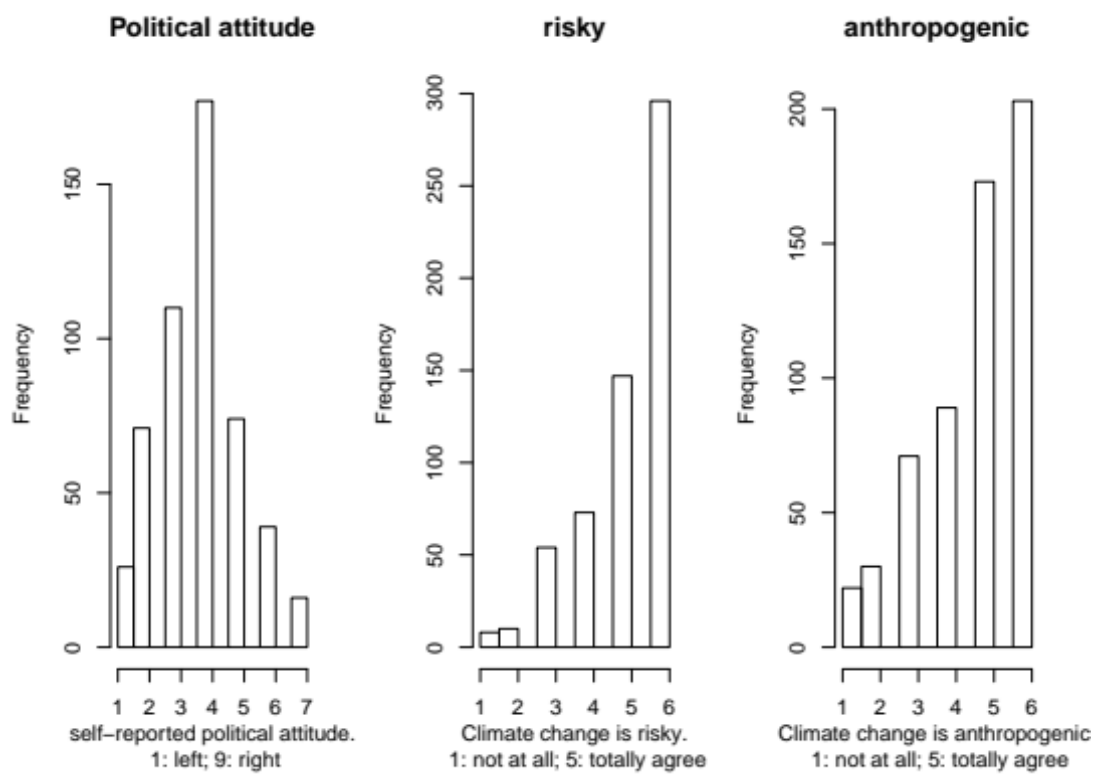

Figure 5. Distributions of self-reported political attitude, beliefs that climate change is risky, and beliefs that climate change is anthropogenic for the sample used in study 2. 
Table 4. Means, standard deviations, and correlations of measures used in study 2.

\begin{tabular}{lcccccc}
\hline Variable & \multicolumn{1}{c}{$\boldsymbol{M}$} & $\mathbf{S D}$ & $\mathbf{1}$ & $\mathbf{2}$ & $\mathbf{3}$ & $\mathbf{4}$ \\
\hline 1. anthropogenic & 4.65 & 1.38 & & & & \\
2. risky & 5.09 & 1.17 & $\begin{array}{c}.61^{* *} \\
{[.56, .66]}\end{array}$ & & & \\
& & & $09^{*}$ & $.09^{*}$ & & \\
3. knowledge (d') & 0.69 & 0.19 & $\begin{array}{c}.01, .17] \\
{[.01, .17]}\end{array}$ & & \\
$\begin{array}{l}\text { 4. meta- } \\
\text { knowledge } \\
\text { (confidence) }\end{array}$ & 0.82 & 0.13 & .03 & $.10^{*}$ & $.46^{* *}$ & \\
& & & {$[-.05, .11]$} & {$[.02, .18]$} & {$[.40, .52]$} & \\
$\begin{array}{l}\text { 5. meta-cognitive } \\
\text { sensitivity } \\
\text { (meta_d) }\end{array}$ & 7.26 & 12.93 & .06 & $.12 * *$ & $.50^{* *}$ & $.47 * *$ \\
& & & {$[-.02, .14]$} & {$[.04, .20]$} & {$[.44, .56]$} & {$[.41, .53]$} \\
\hline
\end{tabular}

Note. $M$ and $S D$ represent mean and standard deviation, respectively. Values in square brackets indicate the $95 \%$ confidence interval. * indicates $p<.05 . * *$ indicates $p<.01$.

\section{To what extent is the predictivity of climate change meta-knowledge domain-specific? To} test in how far the result that climate change meta-knowledge predicted climate change beliefs is domain-specific, we conducted a combined analysis on both data sets produced by study 1 and 2 (total $\mathrm{N}=1097$ ) to test for interaction effects. If confidence in climate change, but not other-science, knowledge predicts climate beliefs, we should see an interaction between knowledge type (study 1: climate change knowledge versus study 2: other-science knowledge) and confidence in that knowledge. All continuous variables were z-transformed within each study, before being entered into joint regression models. We ran the same set of multiple regression models as in study 1 , each predicting the climate change belief of riskiness and anthropogenicity, with science knowledge (d'), political attitude, and demographic variables (gender, age, education) as the baseline model, and entering meta-knowledge (confidence) and sensitivity (meta_d). Additionally, we entered interaction terms between knowledge type and confidence in knowledge (Table 5, Table 6). Results replicated results from study 1 in that the baseline model explained climate change beliefs. Importantly, however, we found interactions between knowledge type and meta-knowledge in that meta-knowledge was 
predictive of climate change beliefs to a considerably larger extent compared to other-science knowledge (Figure 6). These results suggest that confidence in domain-specific, but not other-domain science knowledge relates to climate change beliefs.

Table 5. Multiple regression analyses predicting the belief that climate change is risky with other-science knowledge (d'), meta-knowledge (confidence), metacognitive sensitivity (meta_d) and interaction between study and confidence (study 1: climate change knowledge; study 2: other-science knowledge) as predictors, controlling for political attitude (1: left; 9: right); gender (1= male; 2 = female), age, and education (dummy-coded).

\begin{tabular}{|c|c|c|c|c|}
\hline Predictor & $\boldsymbol{b}$ & $\begin{array}{c}b \\
95 \% \mathrm{CI}\end{array}$ & Fit & Difference \\
\hline (Intercept) & $-0.48^{*}$ & {$[-0.85,-0.10]$} & & \\
\hline d' & $0.20^{* *}$ & {$[0.08,0.32]$} & & \\
\hline Political Attitude & $-0.21 * *$ & {$[-0.27,-0.15]$} & & \\
\hline sex & 0.06 & {$[-0.06,0.18]$} & & \\
\hline age & $0.01 *$ & {$[0.00,0.01]$} & & \\
\hline education & -0.01 & {$[-0.06,0.04]$} & & \\
\hline study & $0.35 *$ & {$[0.06,0.64]$} & & \\
\hline \multirow[t]{2}{*}{$\mathrm{d}^{*}$ study } & -0.12 & {$[-0.27,0.02]$} & & \\
\hline & & & $\begin{array}{l}R^{2}=.073^{* *} \\
95 \% \text { CI[.04,.10] }\end{array}$ & \\
\hline (Intercept) & -0.33 & {$[-0.69,0.04]$} & & \\
\hline d' & $0.09 *$ & {$[0.01,0.17]$} & & \\
\hline Political Attitude & $-0.20 * *$ & {$[-0.26,-0.14]$} & & \\
\hline sex & 0.11 & {$[-0.01,0.23]$} & & \\
\hline age & 0.00 & {$[-0.00,0.01]$} & & \\
\hline education & -0.03 & {$[-0.08,0.02]$} & & \\
\hline confidence & $0.20^{* *}$ & {$[0.11,0.29]$} & & \\
\hline study & 0.17 & {$[-0.11,0.45]$} & & \\
\hline \multirow[t]{2}{*}{ confidence*study } & $-0.13^{*}$ & {$[-0.25,-0.00]$} & & \\
\hline & & & $\begin{array}{l}R^{2}=.090^{* *} \\
95 \% \text { CI[.05,.12] }\end{array}$ & $\begin{array}{l}\Delta R^{2}=.017 * * \\
95 \% \text { CI }[.00, .03]\end{array}$ \\
\hline (Intercept) & -0.32 & {$[-0.68,0.05]$} & & \\
\hline d' & 0.07 & {$[-0.01,0.15]$} & & \\
\hline Political Attitude & $-0.20 * *$ & {$[-0.26,-0.14]$} & & \\
\hline sex & 0.11 & {$[-0.01,0.24]$} & & \\
\hline age & 0.00 & {$[-0.00,0.01]$} & & \\
\hline education & -0.03 & {$[-0.08,0.02]$} & & \\
\hline confidence & $0.20^{* *}$ & {$[0.11,0.29]$} & & \\
\hline study & 0.14 & {$[-0.14,0.42]$} & & \\
\hline \multirow{3}{*}{$\begin{array}{r}\text { meta_d } \\
\text { confidence* study }^{*}\end{array}$} & 0.00 & {$[-0.00,0.01]$} & & \\
\hline & $-0.15^{*}$ & {$[-0.28,-0.02]$} & & \\
\hline & & & $R^{2}=.091^{* *}$ & $\Delta R^{2}=.002$ \\
\hline
\end{tabular}


Note. All continuous variables were z-transformed within each study, before being entered into regression models. $b$ represents unstandardized regression weights. beta indicates the standardized regression weights. * indicates $p<.05 . * *$ indicates $p<.01$.

Table 6. Multiple regression analyses predicting the belief that climate change is anthropogenic with other-science knowledge (d'), meta-knowledge (confidence), metacognitive sensitivity (meta_d) and interaction between study and confidence (study 1: climate change knowledge; study 2: otherscience knowledge) as predictors, controlling for political attitude (1: left; 9: right); gender (1= male; 2 = female), age, and education (dummy-coded).

\begin{tabular}{|c|c|c|c|c|}
\hline Predictor & $\boldsymbol{b}$ & $\begin{array}{c}b \\
95 \% \mathrm{CI} \\
\end{array}$ & Fit & Difference \\
\hline (Intercept) & -0.04 & {$[-0.43,0.35]$} & & \\
\hline d' & $0.23 * *$ & {$[0.11,0.36]$} & & \\
\hline Political Attitude & $-0.18^{* *}$ & {$[-0.24,-0.11]$} & & \\
\hline sex & 0.05 & {$[-0.07,0.17]$} & & \\
\hline age & -0.00 & {$[-0.01,0.00]$} & & \\
\hline education & -0.00 & {$[-0.05,0.05]$} & & \\
\hline study & -0.00 & {$[-0.30,0.30]$} & & \\
\hline \multirow{2}{*}{$\mathrm{d}^{*}$ study } & $-0.19 *$ & {$[-0.34,-0.04]$} & & \\
\hline & & & $\begin{array}{l}R^{2}=.057 * * \\
95 \% \text { CI[.03,.08] }\end{array}$ & \\
\hline (Intercept) & 0.10 & {$[-0.28,0.48]$} & & \\
\hline & $0.11^{* *}$ & {$[0.03,0.18]$} & & \\
\hline Political Attitude & $-0.18^{* *}$ & {$[-0.24,-0.12]$} & & \\
\hline sex & 0.08 & {$[-0.05,0.20]$} & & \\
\hline age & -0.00 & {$[-0.01,0.00]$} & & \\
\hline education & -0.01 & {$[-0.06,0.04]$} & & \\
\hline confidence & $0.14^{* *}$ & {$[0.05,0.23]$} & & \\
\hline study & -0.20 & {$[-0.49,0.08]$} & & \\
\hline \multirow[t]{2}{*}{ confidence*study } & $-0.17 *$ & {$[-0.30,-0.04]$} & & \\
\hline & & & $\begin{array}{l}R^{2}=.061 * * \\
95 \% \text { CI[.03,.08] }\end{array}$ & $\begin{array}{l}\Delta R^{2}=.004 * \\
95 \% \text { CI[-.00, .01] }\end{array}$ \\
\hline (Intercept) & 0.10 & {$[-0.28,0.48]$} & & \\
\hline d' & $0.11 *$ & {$[0.02,0.19]$} & & \\
\hline Political Attitude & $-0.18 * *$ & {$[-0.24,-0.12]$} & & \\
\hline sex & 0.08 & {$[-0.05,0.20]$} & & \\
\hline age & -0.00 & {$[-0.01,0.00]$} & & \\
\hline education & -0.01 & {$[-0.06,0.04]$} & & \\
\hline confidence & $0.14^{* *}$ & {$[0.05,0.23]$} & & \\
\hline
\end{tabular}




$\begin{array}{rllll}\text { study } & -0.20 & {[-0.49,0.09]} & & \\ \text { meta_d } & -0.00 & {[-0.01,0.01]} & & \\ \text { confidence*study } & -0.17^{*} & {[-0.30,-0.03]} & R^{2}=.061^{* *} & \Delta R^{2}=.000 \\ & & & 95 \% \text { CI }[.03, .08] & 95 \% \text { CI }[-.00, .00]\end{array}$

Note. All continuous variables were z-transformed within each study, before being entered into joint regression models. $b$ represents unstandardized regression weights. beta indicates the standardized regression weights. * indicates $p<.05$. ** indicates $p<.01$.

A
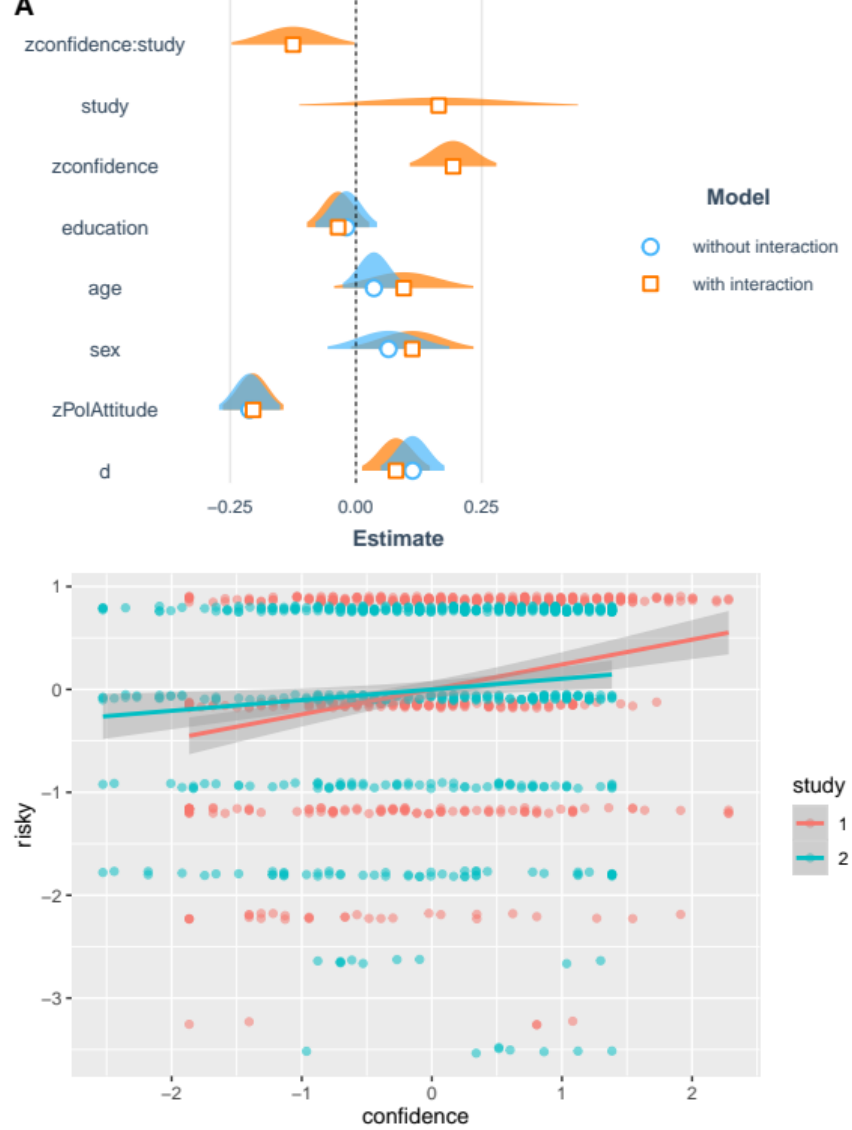

B

zconfidence:study

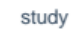

zconfidence

education

age

$\operatorname{sex}$

zPolAttitude

d

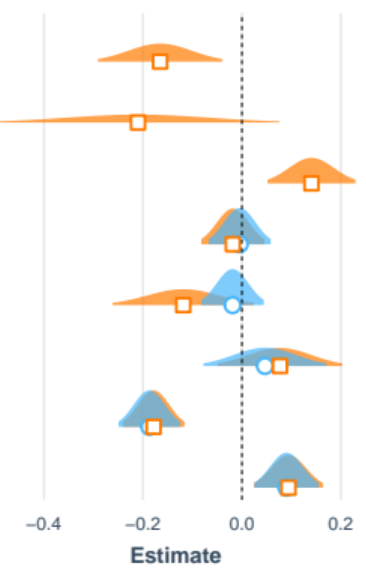

with interaction

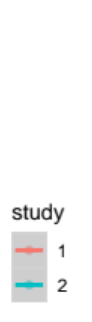

Figure 6. Interaction between knowledge type (study 1: climate change knowledge; study 2: other-science knowledge) and meta-knowledge (confidence) for predicting climate change beliefs (risky, Panel A; anthropogenic, Panel B). Continuous variables are z-transformed. The top row displays the results of two regression models on the list of predictors used in both studies, one model 
with, and one model without an interaction term (study: confidence). The width of the distribution for each predictor indicates 95\% CI. The bottom row visualizes the interaction between knowledge type and confidence for predicting climate change beliefs. Shaded grey area denotes 95\% CI.

Study 2 investigated in how far the predictivity of confidence in climate change knowledge for explaining climate change beliefs is domain-specific. Results showed that while both climate change, and other-domain (biological and physical) science knowledge were predictive of climate change beliefs, respective meta-knowledge was differentially related to climate change beliefs. Specifically, confidence in climate change knowledge was considerably more predictive of climate change beliefs compared to confidence in other-domain science knowledge. This result held for both the belief that climate change is risky, and the belief that climate change is anthropogenic. Furthermore, the relevance of meta-knowledge differed between domain-specific and other-domain knowledge, even though object-level other-domain knowledge itself was related to climate change beliefs as well. Taken together, study 2 results rule out the alternative, domain-general explanation whereby the degree of confidence in science knowledge in general explains climate change beliefs. Study 2 hence suggests that climate change beliefs are shaped by domain-specific meta-knowledge. Or, conversely, that domain-specific meta-knowledge explains knowledge-relevant beliefs, beliefs built on that specific knowledge.

\section{General Discussion}

Although considerable research exists on the role of object-level cognition for explaining beliefs about politicized science such as nanotechnology, vaccination, or climate change, the importance of metacongition is largely unknown. Here we investigate the relevance of meta-knowledge (or confidence in knowledge) for explaining beliefs about one of the most heavily contested examples: Climate change. Frequentist and Bayesian analyses showed that for a national German sample, climate change meta-knowledge was predictive of beliefs, above and beyond object-level climate change knowledge. These results held for both the belief that climate change is risky, and the belief that climate change is anthropogenic, and when controlling for well-known other predictors (political attitude, age, gender, education). Furthermore, for another national sample, we showed that the relationship between climate change meta-knowledge and climate change beliefs is domain-specific: While other-domain science knowledge was related to climate change beliefs as well, confidence in climate change 
knowledge was a stronger predictor of climate change beliefs compared to confidence in other-domain science knowledge, suggesting that outside of the context for which it was relevant, metacognitive confidence did not explain beliefs. These results highlight the relevance of domain-specific metacognition for explaining beliefs about the contested science of climate change.

Emerging evidence has demonstrated the relevance of domain-general metacognition for forming beliefs about political issues (Sinclair ret al., 2019; Zmigrod et al., 2018, 2019), but it has also been argued that other, domain-specific facets of metacognition might be closer to the cognitive mechanisms that shape belief (Rollwage et al., 2018). In line with this proposition, we find a relationship between domain-specific meta-knowledge and climate change belies that are roughly of the size of the relationship between object-level knowledge and beliefs. These results suggest that, for explaining beliefs about controversial science, metacognitive factors that are specific to the respective domain are roughly as important as understanding of the object-level matter itself.

These results contrast previous findings on the predictivity of subjective knowledge. If subjective knowledge were simply a less reliable measure of objective knowledge, then subjective measure should simply add noise to objective measures, and subjective measures should not be able to explain variance above and beyond the variance explained by objective knowledge measures. And indeed, previous research found no incremental predictive value above and beyond objective knowledge (Stoutenborough \& Vedlitz, 2014). The present results, however, suggest that when measured using entire scales, rather than one-item assessment, subjective confidence in climate change knowledge is not simply a less reliable measure of objective knowledge; it is a different measure with explanatory value in its own right that captures additional aspects of knowledge that are not captured by objective measures alone.

Interestingly, sensitivity of confidence, albeit showing a first-order relationship with climate change beliefs in the order of $[.05, .22]$ and $[.06, .23]$ (for anthropogenicity and risk, respectively), did not explain climate change beliefs when controlling for knowledge, political attitude, and confidence. This result constitutes an interesting divergence from previous findings into domain-general metacognition measured with perceptual discrimination, where sensitivity explained politically radical beliefs above and beyond task performance and confidence (Rollwage et al., 2018). An obvious difference between both studies pertains to the type of judgments as either about the accuracy of lowlevel perception, or the accuracy of prior knowledge. A vast majority of research has demonstrated the malleability of memory-based judgments, where memory is constructed in light of current world views 
(Chew et al., 2019; Saucet \& Villeval, 2019; Schacter \& Coyle, 1997). Such motivated memory effects are, almost by definition, ruled out when judging the accuracy of low-level perception unrelated to world views. Although this is for future research to decide, motivated memory effects might distort metacognitive judgments about the accuracy of one's climate change knowledge, and hence render the (objective) accuracy of memory-based judgments less predictive of climate change beliefs compared to the (subjective) confidence with which they are made.

Previous research has shown that political attitude moderates the relationship between scientific literacy and climate change beliefs (Drummond \& Fischhoff, 2017; Kahan, 2012). However, these results mostly stem from US samples, and considerably less is known about a potentially polarizing effect of scientific knowledge for non-US samples. Here we show for two independent national German samples, that while climate change was politicized in that political attitude was related to climate change beliefs, we found no evidence for a polarizing effect of knowledge. Rather, climate change knowledge was positively related to climate change beliefs, across the political spectrum. In a word, climate change was politicized, but knowledge was not polarizing. These result highlight the need for non-US samples to reveal the full spectrum of politicized science, and the potentially polarizing effect of scientific knowledge across societies. Furthermore, our results demonstrate how politicization and polarization over controversial science are very distinct societal processes that do not necessarily occur simultaneously.

To conclude, the present results highlight the importance of domain-specific meta-knowledge for explaining beliefs about the contested issue of climate change. By demonstrating the relevance of metacognitive, rather than solely object-level thought, these results add to our understanding of the cognitive processes involved in the formation of beliefs about politicized science. 


\section{References}

Allgood, S., \& Walstad, W. B. (2016). The effects of perceived and actual financial literacy on financial behaviors. Economic Inquiry, 54(1), 675-697.

Baldiga, K. (2013). Gender differences in willingness to guess. Management Science, 60(2), 434-448.

Bord, R. J., O’Connor, R. E., \& Fisher, A. (2000). In what sense does the public need to understand global climate change? Public Understanding of Science, 9(3), 205-218.

Chew, S. H., Huang, W., \& Zhao, X. (2019). Motivated false memory. Available at SSRN 2127795.

Douglass, A. B., \& Steblay, N. (2006). Memory distortion in eyewitnesses: A meta-analysis of the postidentification feedback effect. Applied Cognitive Psychology, 20(7), 859-869.

Drummond, C., \& Fischhoff, B. (2017). Individuals with greater science literacy and education have more polarized beliefs on controversial science topics. Proceedings of the National Academy of Sciences, 114(36), 9587-9592.

Fischer, H., Amelung, D., \& Said, N. (2019). The accuracy of German citizens’ confidence in their climate change knowledge. Nature Climate Change, 1-5.

Fleming, S. M. (2017). HMeta-d: Hierarchical Bayesian estimation of metacognitive efficiency from confidence ratings. Neuroscience of Consciousness, $2017(1)$, nix007.

Fleming, S. M., \& Lau, H. C. (2014). How to measure metacognition. Frontiers in Human Neuroscience, 8, 443.

Hadar, L., Sood, S., \& Fox, C. R. (2013). Subjective knowledge in consumer financial decisions. Journal of Marketing Research, 50(3), 303-316.

Hornsey, M. J., Harris, E. A., Bain, P. G., \& Fielding, K. S. (2016). Meta-analyses of the determinants and outcomes of belief in climate change. Nature Climate Change, 6(6), 622.

Kahan, D. M. (2012). Ideology, motivated reasoning, and cognitive reflection: An experimental study. https://papers.ssrn.com/sol3/papers.cfm?abstract id=2182588

Kube, T., \& Rozenkrantz, L. (2020, March 24). When our beliefs face reality: An integrative review of belief updating in mental health and illness. https://doi.org/10.31234/osf.io/cy64r 
Malka, A., Krosnick, J. A., \& Langer, G. (2009). The association of knowledge with concern about global warming: Trusted information sources shape public thinking. Risk Analysis, 29(5), 633647.

Maniscalco, B., \& Lau, H. (2014). Signal detection theory analysis of type 1 and type 2 data: Meta-d', response-specific meta-d', and the unequal variance SDT model. In The cognitive neuroscience of metacognition (pp. 25-66).

McCright, A. M., \& Dunlap, R. E. (2011a). Cool dudes: The denial of climate change among conservative white males in the United States. Global Environmental Change, 21(4), 11631172.

McCright, A. M., \& Dunlap, R. E. (2011b). The politicization of climate change and polarization in the American public’s views of global warming, 2001-2010. The Sociological Quarterly, 52(2), 155-194.

Ortoleva, P., \& Snowberg, E. (2015). Overconfidence in political behavior. The American Economic Review, 105(2), 504-535.

Rollwage, M., Dolan, R. J., \& Fleming, S. M. (2018). Metacognitive failure as a feature of those holding radical beliefs. Current Biology, 28(24), 4014-4021.

Saucet, C., \& Villeval, M. C. (2019). Motivated memory in dictator games. Games and Economic Behavior, 117, 250-275.

Schacter, D. L., \& Coyle, J. T. (1997). Memory distortion: How minds, brains, and societies reconstruct the past. Harvard University Press.

Shi, J., Visschers, V. H., Siegrist, M., \& Arvai, J. (2016). Knowledge as a driver of public perceptions about climate change reassessed. Nature Climate Change, 6(8), 759-762.

Stoutenborough, J. W., \& Vedlitz, A. (2014). The effect of perceived and assessed knowledge of climate change on public policy concerns: An empirical comparison. Environmental Science \& Policy, 37, 23-33. 
Sundblad, E.-L., Biel, A., \& Gärling, T. (2009). Knowledge and confidence in knowledge about climate change among experts, journalists, politicians, and laypersons. Environment and Behavior, 41(2), 281-302.

Tobler, C., Visschers, V. H., \& Siegrist, M. (2012). Consumers’ knowledge about climate change. Climatic Change, 114(2), 189-209.

Wetzels, R., Matzke, D., Lee, M. D., Rouder, J. N., Iverson, G. J., \& Wagenmakers, E.-J. (2011). Statistical evidence in experimental psychology: An empirical comparison using 855 t tests. Perspectives on Psychological Science, 6(3), 291-298.

Wolfe, M. B., \& Williams, T. J. (2018). Poor metacognitive awareness of belief change. Quarterly Journal of Experimental Psychology, 71(9), 1898-1910.

Zmigrod, L., Rentfrow, P. J., \& Robbins, T. W. (2018). Cognitive underpinnings of nationalistic ideology in the context of Brexit. Proceedings of the National Academy of Sciences, 115(19), E4532-E4540.

Zmigrod, L., Rentfrow, P. J., \& Robbins, T. W. (2019). Cognitive inflexibility predicts extremist attitudes. Frontiers in Psychology, 10, 989. 